\title{
Identification of a Functional Type IA Topoisomerase, LdTopIII $\beta$, from Kinetoplastid Parasite Leishmania donovani
}

\author{
Bijoylaxmi Banerjee, ${ }^{1}$ Nilkantha Sen, ${ }^{2}$ and Hemanta K. Majumder ${ }^{1}$ \\ ${ }^{1}$ Molecular Parasitology Laboratory, Infectious Disease and Immunology Division, Indian Institute of Chemical Biology, \\ 4, Raja S. C. Mullick Road, Kolkata 700032, India \\ ${ }^{2}$ Solomon H. Snyder Department of Neuroscience, Johns Hopkins University School of Medicine, Baltimore, MD 21205, USA
}

Correspondence should be addressed to Hemanta K. Majumder, hkmajumder@iicb.res.in

Received 24 December 2010; Accepted 25 February 2011

Academic Editor: Elena Gonzalez-Rey

Copyright (C 2011 Bijoylaxmi Banerjee et al. This is an open access article distributed under the Creative Commons Attribution License, which permits unrestricted use, distribution, and reproduction in any medium, provided the original work is properly cited.

DNA topoisomerases of kinetoplastids represent a family of DNA processing enzymes that essentially solve the topological problems not only in nuclear DNA but also in kinetoplast DNA. We have, for the first time, identified a Leishmania donovani homologue of bacterial and eukaryotic IA type of topoisomerase III protein and termed as $L d$ TopIII $\beta$. Complementation study of wild-type and mutant $L d$ TopIII $\beta$ with slow-growing topoisomerase III mutant yeast $S$. cerevisiae revealed the functional conservation of the leishmanial counterpart of topoisomerase III $\beta$ protein, the 327 tyrosine being the active site amino acid. A C-terminal deletion construct of $L d$ TopIII $\beta$ could not suppress the slow-growth phenotype of mutant yeast, indicating the requirement of $\mathrm{C}$-terminal region for the enzyme function in vivo. LdTopIII $\beta$ localized inside the nucleus and kinetoplast of the parasite. Taken together, our study indicates functional conservation and possible role of $L d$ TopIII $\beta$ in parasite DNA processing.

\section{Introduction}

DNA topoisomerases are ubiquitous enzymes found in all prokaryotic and eukaryotic cells and in some viruses. They are involved in all aspects of DNA metabolism such as replication, transcription, recombination, and chromosome segregation $[1,2]$. These reactions are based on sequential breakage and rejoining of the DNA phosphodiester backbone [2-4]. Type I DNA topoisomerases catalyze the cleavage of one strand of DNA, whereas type II DNA topoisomerases catalyze the cleavage of a double-stranded DNA, requiring ATP as a cofactor [4].

Type I DNA topoisomerases are further classified in two subfamilies, IA and IB, based on differences in amino acid sequence and reaction mechanisms [5]. The type IA enzymes link covalently to cleaved DNA through the $5^{\prime}$-phosphate. They are represented by bacterial topoisomerase I and III and the eukaryotic topoisomerase III enzymes. Type IB topoisomerases, exemplified by eukaryotic topoisomerase I, in contrast, become attached to $3^{\prime}$-phosphate end of the cleaved strand of the DNA [4]. Type IA topoisomerases are highly conserved from bacteria to humans.
While the function of topoisomerase II and I are quite well established, the role of topoisomerase III in DNA metabolism is still being defined. Genes encoding topoisomerase III enzymes are highly conserved in evolution from bacteria to human, and the phenotypic consequences of loss of topoisomerase III function are generally quite severe. It has been shown to possess a weak, ATP-independent relaxation activity towards negatively supercoiled DNA only and strict dependence on magnesium [6].

The E. coli chromosome encodes two type IA topoisomerase, DNA topoisomerase I [7] and topoisomerase III $[8,9]$. Loss of topoisomerase III in E. coli results in an increase in deletions arising from recombination events between direct repeats $[10,11]$. Yeast cells express a single type IA topoisomerase, topoisomerase III encoded by the Top3 gene. In S. pombe, top 3 is essential for viability and plays a role in chromosome segregation [12]. It has been shown that top3-ts mutant $S$. pombe cells are sensitive to the DNA damaging agents UV and MMS (methyl methanesulfonate) at the restrictive temperature revealing that topoisomerase III is involved in DNA damage survival [13]. In S. cerevisiae, top $3 \Delta$ mutants are viable, but very slow-growing and have 
defects in S phase responses to DNA damage and in both mitotic and meiotic recombination $[14,15]$. In vertebrates, there are two isoforms of topoisomerase III enzymes termed $\alpha$ and $\beta$ [16-19]. Deletion of mouse topoisomerase III $\alpha$ gene led to embryonic lethality [20]. Deletion of mouse topoisomerase III $\beta$ gene displayed shortened lifespan and infertility [21,22].

DNA topoisomerases of kinetoplastids represent a family of DNA processing enzymes that essentially solve the topological problems not only in the nuclear DNA but also in the kinetoplastid DNA. The IB type of bi-subunit topoisomerase I and topoisomerase II of the parasites which maintain vital cellular processes, are also proven target for clinically useful antitumor drugs [23]. Apart from this IB type of topoisomerase I, three type IA topoisomerases are there in the parasite genome, termed as topoisomerase IA, and two topoisomerase III. Topoisomerase IA of T. brucei has been reported and shown to be mitochondrial and essential for late theta structure resolution [24]. Very recently, a Topoisomerase III $\alpha$ from T. brucei has been shown to play a critical role in antigenic switching [25]. In the present study, for the first time, we have identified functionally active DNA topoisomerase III $\beta$ from kinetoplastid parasite $L$. donovani, which localized both inside the nucleus and kinetoplast of the parasite and rescued the topoisomerase III mutant yeast from slow-growth phenotype.

\section{Materials and Methods}

2.1. Parasite Culture and Maintenance. L. donovani strain AG 83 promastigotes were grown at $22^{\circ} \mathrm{C}$ in M199 liquid media supplemented $10 \%$ heat inactivated fetal calf serum. Transfected cells were maintained under the same conditions with $100 \mu \mathrm{g} / \mathrm{mL}$ G418.

2.2. Strains, Media, and Growth Conditions. The Escherichia coli strains used were DH5 $\alpha$ and BL21 (DE3) pLysS. If required, ampicillin and chloramphenicol were used at 100 and $34 \mu \mathrm{g} / \mathrm{mL}$ final concentrations, respectively. The yeast strains used in the studies were W5909-3B (MAT alpha trp11 his3-11, 15 leu2-3, 112 ura3-1 RAD5 LYS2 MET15 ADE2) and W2633-4C (a/alpha top3:: TRP1/+) (kindly gifted by Dr. R Rothstein). The yeast cells were grown at $25^{\circ} \mathrm{C}$ on YEPD medium containing $1 \%$ peptone, $2 \%$ yeast extract, $2 \%$ dextrose and $1.5 \%$ agar or synthetic minimal media as required.

2.3. Cloning of Topoisomerase III $\beta$ Gene from Leishmania donovani. LdTopIII $\beta$ gene was PCR amplified from the genomic DNA of $L$. donovani parasites using the sense primer 5'-GGAAATTCCATATGGGCCGCA ATGTGTTGATG-3' and antisense primer $5^{\prime}$-CGGGATCCTCACCTGCGATCCTCGCGGTTGCC-3' and was cloned in bacterial expression vector pET16b in $N d e 1$ and $B a m H 1$ restriction sites, termed as LdTopIII $\beta-p E T 16 b$.

2.4. Structural Analysis and Homology Modeling. Multiple sequence alignment of $L d$ TopIII $\beta$ sequences from various species was carried out using CLUSTAL W (http://expasy .org/tools). Three-dimensional models of $L d$ TopIII $\beta$ based on the crystal structure of E. coli topoisomerase III were generated using Swiss Prot (http://expasy.org/sprot). The generated files were opened in RasMol (http://www.rasmol.org/). The protein sequences were represented in ribbon format and the active site residues were represented in ball and stick format over the ribbon structure.

2.5. Construction of Expression Vectors and Transfection in Leishmania. LdTOPIII $\beta$ genes was PCR amplified using $L d T o p I I I \beta-p E T 16 b$ as templates and was subcloned using the sense primer $5^{\prime}$-CGGGATCCATGGGCCGCA ATGTGTTGATG-3' and antisense primer 5' -GATATCCCTGCGATCCTCGCGGTTGCC-3' in BamH1 and EcoRV sites of Leishmania transfection vector pXG-B2863 (a kind gift from Dr. S. M. Beverley), to produce C-terminal-GFP-tagged fulllength $L d$ TopIII $\beta$ protein and termed as LdTopIII $\beta$-GFP. The constructs and empty vector pXG-B2863 were transfected into $L$. donovani promastigotes separately by electroporation as described earlier [26]. Briefly, late log-phase promastigotes were harvested and washed twice in OPTI-MEM (GIBCO). Cells were finally suspended at a density of $1 \times 10^{8} / \mathrm{mL}$ and $0.4 \mathrm{~mL}$ was taken into a $0.2 \mathrm{~mm}$ ice-chilled electroporation cuvette. Thirty microgram of plasmid DNA was taken in $100 \mu \mathrm{L}$ of electroporation buffer and added to the cells. After $10 \mathrm{~min}$ on ice, the cells were electroporated with a single pulse by Bio-Rad Gene Pulsar apparatus using $450 \mathrm{~V}$ and $550 \mu \mathrm{F}$ capacitance. The cells were incubated on ice for further $5 \mathrm{~min}$ and then added to $10 \mathrm{~mL}$ of drugfree growth medium. After $24 \mathrm{~h}$ of survival $10 \mu \mathrm{g} / \mathrm{mL}$ G4 18 was added and kept at $22^{\circ} \mathrm{C}$. The transfected cells were monitored visually by microscope and drug concentration was increased gradually. Finally the transfected cells were routinely maintained in medium containing $100 \mu \mathrm{g} / \mathrm{mL}$ G418.

2.6. Fluorescence Microscopy. Localization of C-terminal GFP tagged chimeric $L d$ TopIII $\beta$-GFP protein was visualized by fluorescence microscopy (Olympus IX81). Cell nucleus and kinetoplast were stained with DAPI. Differential visualization of the fluophores was achieved using a $488 \mathrm{~nm}$ excitation filters and $523 \mathrm{~nm}$ emission filter for GFP and $258 \mathrm{~nm}$ excitation and $361 \mathrm{~nm}$ emission filter for DAPI.

2.7. Construction of Mutants. The full-length LdTopIII $\beta$ was subcloned in $\mathrm{XbaI}$ and $\mathrm{BamH1}$ sites into the yeast shuttle vector pVT100U, a kind gift from Dr. Rolf Sternglanz [27] and termed as LdTopIII $\beta$ - $p V T$ using the sense primer 5'-GCTCTAGAATGGGCCGCAATGTGTTGATG-3' and antisense primer $5^{\prime}$-CGGGATCCTCACCTGCGATCCTCGCGGTT-3'. For construction of C-terminal deletion construct of $L d T o p I I I \beta$, regions corresponding to amino acids 1-608 was PCR amplified using the primers $5^{\prime}$ GCTCTAGAATGGGCCGCAATGTGTTGATG-3' (sense) and $5^{\prime}$-CGGGATCCGGCGGCGGAGATGGCGGAGAA-3' (antisense) and was cloned in Xbal and BamH1 sites of pVT100U vector. 
2.8. Site-Directed Mutagenesis. Single mutations were introduced in LdTOPIII $\beta$ at position Tyr 327 (Y327). Mutagenesis was performed by using the QuikChangeXL site-directed kit (Stratagene, La Jolla, CA) according to the manufacturer's protocol. To carry out the desired mutations, LdTopIII $\beta$ $p V T$ was used as templates for all mutagenesis experiments. For each mutation, the wild-type nucleotide was replaced using a specific pair of mutagenic primers. The following sense primer, along with the antisense counterparts (with codons in boldface and substitutions underlined), were used; for Y327 of LdTopIII $\beta$, sense primer was 5' -CCGCGGCTATATTTCGTTCCCTCGTACCCGAATCC- $3^{\prime}$ and antisense primer was 5'-GGATTCGGTACGAGGGAACGAAATATAGCCGCGG-3'.

2.9. Complementation Assay. The top 3 mutant yeast strain W2633-4C (a/alpha top3:: TRP1/+) (a kind gift from Dr. R Rothstein) was used for transformation with recombinant topo III proteins from $L$. donovani by the lithium acetate and polyethylene glycol method [28]. The transformants were cultured on solid synthetic minimal medium at $30^{\circ} \mathrm{C}$ for 2 days. Colonies were picked and cultured in tubes with $2 \mathrm{~mL}$ of synthetic minimal media at $30^{\circ} \mathrm{C}$ overnight.

2.10. Expression of Recombinant LdTopIII $\beta$ Using the Expressway Cell-Free E. coli Expression System (Invitrogen). In vitro transcription and translation of $L d T$ TopIII $\beta$ proteins were carried out according to the manufacturer's protocol. LdTopIII $\beta$ - $p E T 16 b$ plasmids were used as DNA templates for synthesis of the protein. After the reaction is over, the crude bacterial lysate containing the newly synthesized protein was tested for activity.

2.11. DNA Relaxation Activity by LdTopIII $\beta$. The type IA DNA topoisomerases were assayed by decreased mobility of the relaxed isomers of supercoiled pBS (SK+) [pBluescript $(\mathrm{SK}+)]$ DNA in an agarose gel. Relaxation assay was carried out with the crude lysates containing the in vitro transcribed and translated $L d$ TopIII $\beta$. Supercoiled pBS DNA (85\%-95\% were negatively supercoiled with the remaining being nicked circles) was used as substrate in the relaxation buffer $(25 \mathrm{mM}$ Tris-HCl, pH 7.5, $5 \%$ glycerol, $0.5 \mathrm{mM}$ DTT, $2 \mathrm{mM} \mathrm{MgCl}_{2}$, $50 \mu \mathrm{g} / \mathrm{mL}$ BSA). The amount of supercoiled monomer DNA band fluorescence after $\operatorname{EtBr}(0.5 \mu \mathrm{g} / \mathrm{mL})$ staining was visualized using Gel Doc 2000 under UV illumination (BioRad Quality one Software).

\section{Results}

3.1. Type IA Topoisomerase Genes in Leishmania. A search of the Leishmania major genome database yielded three type IA topoisomerases. One is on chromosome 21, annotated as topoisomerase IA (LmjF21.0125) with an ORF of $2453 \mathrm{bp}$. Two other type IA topoisomerases are present on chromosome 28 and 36, respectively, both of which are annotated as topoisomerase III (LmjF28.1780 and LmjF36.3200, resp.).
3.2. Identification of Topoisomerase III Genes in Leishmania donovani. One of the two topoisomerase III genes present in L. major geneDB is $2601 \mathrm{bp}$ ( $\mathrm{LmjF} 28.1780$ ) and encodes a $95 \mathrm{kDa}$ predicted protein. The other topoisomerase III ORF (LmjF36.3200) is $2844 \mathrm{bp}$, and encodes a $104 \mathrm{kDa}$ predicted protein. Topoisomerase III gene with $2601 \mathrm{bp}$ was PCR amplified from the genomic DNA of $L$. donovani, cloned and sequenced (GeneBank accession number GQ499197). Blast analysis of the sequence confirmed the topoisomerase III lineage of the protein and henceforth referred as LdTopIII $\beta$. The alignment of $L d$ TopIII $\beta$ with $S$. cerevisiae and S. pombe topoisomerase III and human topoisomerase III is shown in Figure 1. The active site tyrosine is located at the 327 position within a highly conserved GYISYPRTES sequence. The protein has $46.22 \%$ identity and $76.09 \%$ similarity with human topoisomerase III $\beta$. It contains seven CXXC sequences instead of eight found in other topoisomerase III $\beta$ proteins. The intervening spacers are also highly conserved. Glycine $(\mathrm{G})$ and arginine $(\mathrm{R})$ rich clusters at the C-terminus end, which is another hallmark of topoisomerase III $\beta$, are also present. It has a continuous stretch of $19 \mathrm{G}$ and $\mathrm{R}$ residues in the $\mathrm{C}$-terminus. Three-dimensional structure generated by Swiss Prot has been shown in Figure 2(a). Figure 2(b) shows the magnified view of the active site. The conserved amino acid residues are represented in ball and stick format and have been labeled. Homology comparisons of $L d \operatorname{TopIII} \beta$ with other IA type of topoisomerases have been provided in Table 1, which strongly indicates its topoisomerase III lineage.

3.3. Localization Study of LdTopIII $\beta$-GFP. In silico search was carried out to determine possible localization of $L d \operatorname{TopIII} \beta$ protein. A 0.244 probability of mitochondrial transport was predicted by Mitoprot (http://expasy.org/tools) analysis and $73.9 \%$ cytoplasmic and $17.4 \%$ nuclear distribution was revealed by PSORT II analysis (http://expasy.org/tools). To determine the precise localization of the protein, full-length $L d T$ TopIII $\beta$ (865 aa) was cloned in Leishmania expression vector as a C-terminal fusion protein with GFP, termed as $L d$ TopIII $\beta$-GFP, and the construct was transfected in $L$. donovani parasites. Localization of $L d$ TopIII $\beta$-GFP was viewed under fluorescence microscopy (Figure 3(a)). Nucleus and kinetoplast DNA was stained with DAPI (Figure 3(b)). Comparison of DAPI and GFP fluorescence and merged images (Figure 3(c)) revealed that $L d \operatorname{TopIII} \beta$ protein localized both inside the nucleus and kinetoplast of the parasites. Figures 3(d) and 3(e) show cytoplasmic distribution of control GFP protein in $L$. donovani parasites.

3.4. LdTopIII $\beta$ Suppresses the Yeast top $3 \Delta$ Slow-Growth Phenotype. Mutation of the S. cerevisiae top 3 gene is known to result in several phenotypes, including a growth rate which is only $50 \%$ that of wild-type [14]. In order to assess whether the $L d$ TopIII $\beta$ possesses functional similarity to the yeast topoisomerase III, we have used a functional complementation assay of $L d$ TopIII $\beta$ protein to rescue top 3 mutant $S$. cerevisiae strain from slow-growing phenotype. We have cloned the LdTOPIII $\beta$ gene in a shuttle vector $\mathrm{pVT100U}$ 


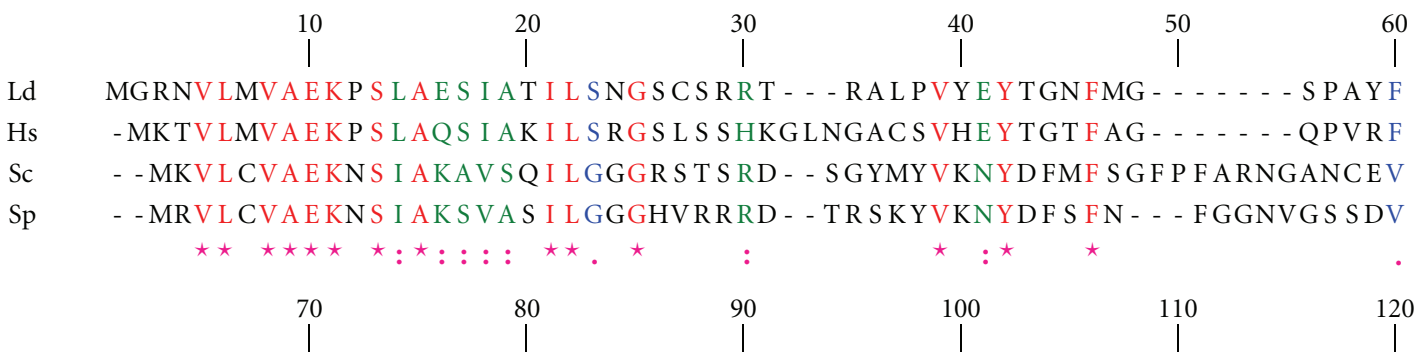

Ld

$\mathrm{Hs}$

Sc

Sp

Ld

Hs

Sc

$\mathrm{Sp}$

Ld

$\mathrm{Hs}$

$\mathrm{Sc}$

$\mathrm{Sp}$

$\mathrm{Ld}$

Hs

Sc

$\mathrm{Sp}$

Ld

$\mathrm{Hs}$

Sc

Sp

$\mathrm{Ld}$

$\mathrm{Hs}$

Sc

Sp

KVT S T T GHV F S CD F T S QHQNWDR TDE EQL F T A P I TWKDT S G - - KVTHHL EHEAQGCDT L KMT S VCGHVMT L D F L GKYNKWDKVDP A E L F S QA P T E KK E AN P K LNMV K F L QVEGR GCDY I TMT S VAGHL TG I D F S HD S HGWGKCA I QE L F DA P LNE I MNNNQK - K I A SN I KREARNADY L TMT S V S GHL T EA S F P S EY S SWS S VPQDVL F DAQ I I T S V S KNAE - VLADN I KKEARNAQY L

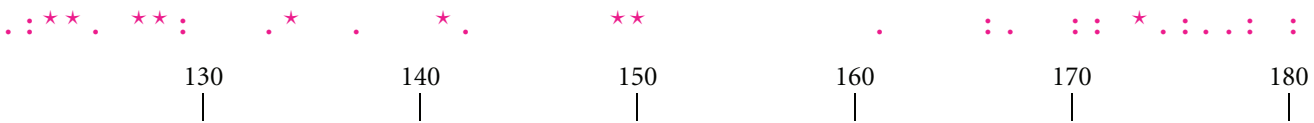
VLWLDCDREGEN I C F EVMQVVRRE I YNHHN - - - - I FRAHF S A T AEE I FQAFRNLGKPNK VLWLDCDKEGEN I C F EVLDAVL PVMNKAHGGEKTVFRAR F S S I TDTD I CNAMACLGE PDH MIWTDCDREGEY I GWE IWQE AKRGNR L I QNDQ - - VYRAV F S HL ERQH I LNAARNP S R LDM Y IWTDCDREGEHI GVE I SNVARASNPS I Q - - - - V I RADFNNLERSHI I SAAKRPRDVSK

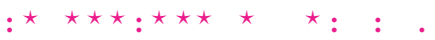

$\begin{array}{cccccc}190 & 200 & 210 & 220 & 230 & 240 \\ \mid & \mid & \mid & \mid & \mid\end{array}$

N I SDAVTCRQE LDLKVGVAFTRFQTKYFQGKYG - . . . . . . . - . DLDASVISYGP NEA L SVDARQE LDLR I GCAFTRFQTKYFQGKYG - . . . . . . . . . DLDS S L I S FGP KSVHAVGTR I E I D L RAGVT F T R L L T E T L RNK L RNQA TMT KDGAKHRGGNKNDSQVVSYGT NAADAVDAR I ELDFRLGA I FTRLQT IQLQKS FD - . - I LQN - . . . . . - - K I I SYGP

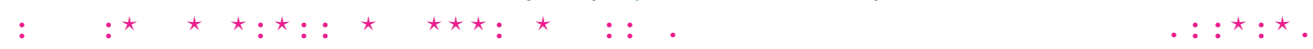

$\begin{array}{ccccc}250 & 260 & 270 & 280 & 290 \\ \mid\end{array}$
CQT P T L GF CVQRHDE I LNFKP ENFWR LVP - VA - S RGGA L LQF EWDRGR L FDETMARL I LQ CQT P T L GFCVERHDK I QS F K P ETYWV LQAKVN - TDKDR S L L LDWDRVRVFDRE I AQMF LN CQF P T L GFVVDR F ER I RN F VP E E FWY I QLVVENKDNGGT T T F QWDRGH L FDR L S V L T F Y E CQF P T L GFVVDRWQRVED F VP ETYWHLRFVD - - KRQGKT I QF NWERAKVFDR L T TMI I L E

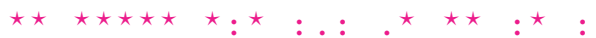
$::^{\star}:{ }^{\star}::^{\star} \star$

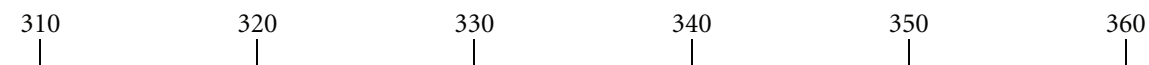
R I T KNGK - VA TVVNVS VS NDTR P R P TGLNTVDLMK I A S RA L G I GPHYVMS I A ENLY I RGY - MTKLEK - EAQVEAT S RKEKAKQRP L A LNTVEMLRVA S S S L GMGPQHAMQTAER L Y TQGY TC I ETAGNVAQVVDLKS KP T TKYRP L P L T TVE LQKNCARY L R LNAKQS LDAAEKLYQKGF NCLECK - - TAKVVN I TQKPKTKYKP LP L S TVELTKLGPKHLR I S AKKT LE LAENLYTNGF

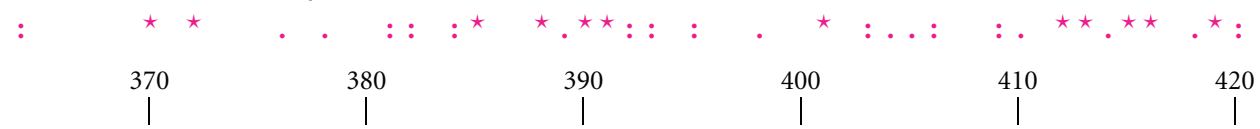

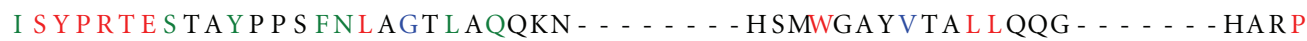

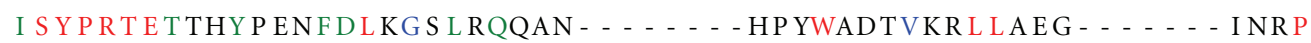
I S Y P RTETDT F PHAMD L K S LVEKQAQLDQLAAGGRT AWA S YAA S L LQP ENT SNNNKF KF P VS Y PRTETDQF D S SMNLHA I I QKL T - . - . - G - AQEWDS YAEGL LAG - - - - - DYRPP $: \star \star \star \star \star \star ⿱: \quad:::^{\star} \quad$ : : :

$\begin{array}{cccccc}430 & 440 & 450 & 460 & 470 & 480\end{array}$

KAG - KDAGDHP P I T PMR S A S - PGE L S GDEWR I F EY I TRHF I A S V S PDCRL I KT K I T I E L G RKG - HDAGDHP P I T PMK S A T - EA E L GGDAWR L YEY I TRHF I A TV SHDCKY LQS T I S F R I G R S GSHDDKAHP P I HP I V S LGP EANVS PVERRVY EYVARHF L ACC S EDAKGQSMT LVLDWA RKGKHNDRAHP P I HPVQMVHR S A L P S QDHWKVY E L I T R R F L ACC S DNAKGAE T L VQVKME

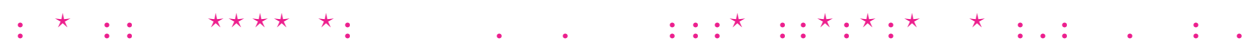

Figure 1: Continued. 


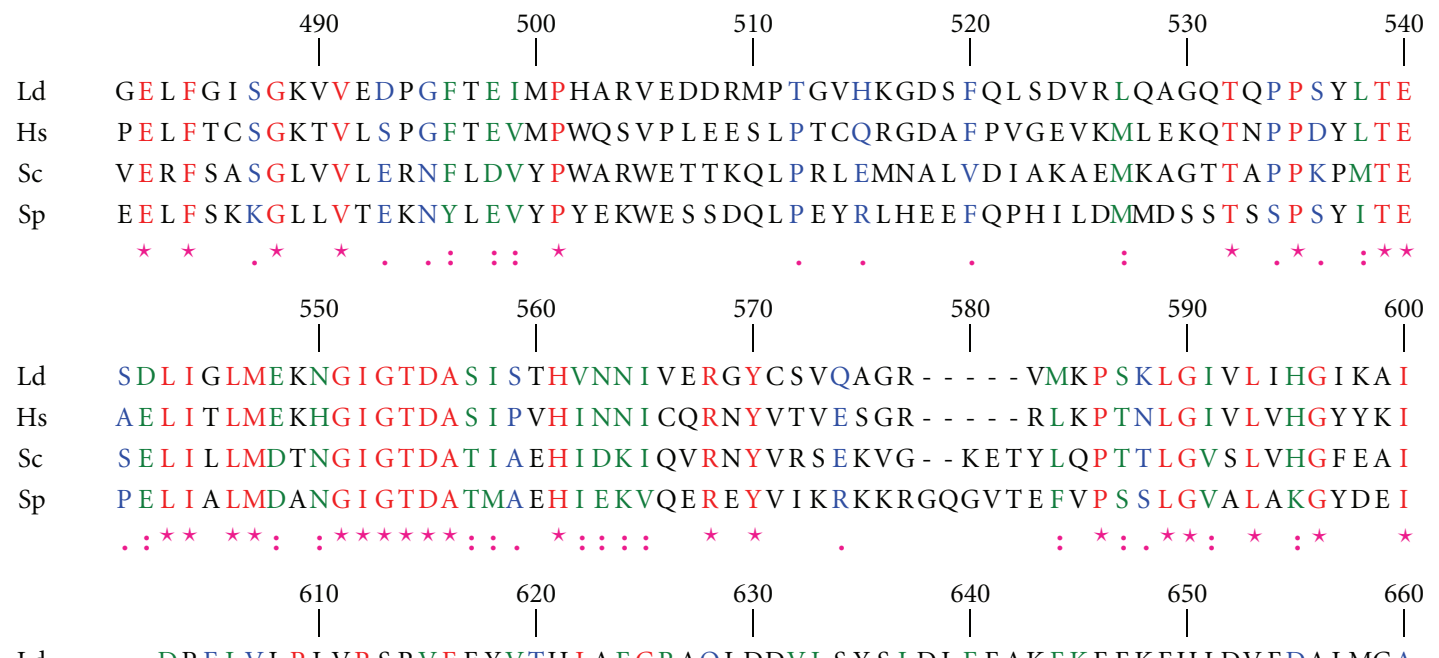

Ld

Hs

Sc

Sp

Ld

$\mathrm{Hs}$

Sc

Sp

d

$\mathrm{Hs}$

Sc

Sp

Ld

$\mathrm{Hs}$

Sc

Sp

Ld

Hs

Sc

Sp

Ld

$\mathrm{Hs}$

Sc

Sp

- - DPE LVL P LVR S RVEEYVTH I A EGRAQLDDV L S Y S LDL F F AKF K F F KEH I DVFDA LMGA

- - DAE LVLPT I R S AVEKQLNL I AQGKADYRQVLGHT LDVFKRKFHYFVDS I AGMDE LMEV GLEDS FAKP FQR R EMEQDLKK I CEGHA S KTDVVKD I VEKYRKYWHKTN - - - ACKNT L LQV GLEWS L TKP F L RKEMEVQLKN I ENGQLNRNVLVHM I L TQF RDV FHL TKQR F DC L KNSCRV
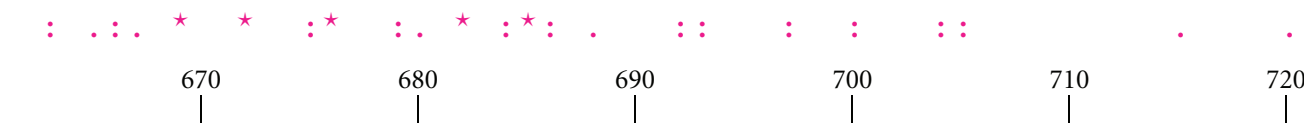

S F S A I S AAGKP I T RCGNCMRYLKHLDTRPQR L YCPYCEVT FA L PQGGA I KPY S S F KCP I D S F S P LAATGK P L S RCGKCHR FMKY I QAKP S R LHC S HCDE TYT L PQNGT I K L Y KE L RCP LD

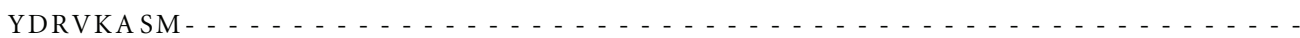

Y LMS HNE PQT -

730

740

750

|

760

I

770

780

NF E LV I CH I EG - GK S F P I C PHCYNNP P F EDMR P A I QHHHRGYGGGAAA TMA P S T RHMA CD DF E LVLWS S G S RGK S Y P L C PYCYNHP P F RDMK . . . . . . . . . . . . . . KGMGCN

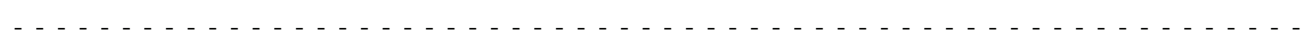

- - . - . - -

I

E CRHP T CEHS L A TNY VCDCVDG S CAG SMA F V P R T T GQWKV CCNKC PMM I K L P P T AQRVYV

E CTHP S CQH S L SML G I GQCVE C E S G - V LV LD P T S G P KWKV ACNKCNVVAHC F ENAHRVRV
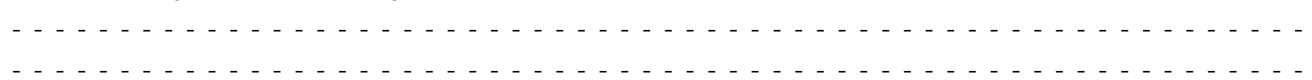

$\begin{array}{rrrrr}850 & 860 & 870 & 880 & 890\end{array}$

|

T S E ECP ECAANCLD IMF P EGK S VL PNRKDR I VAC I FCHPGL S P LCE EVRGR I GN - FRR I G

S ADTC S VCEAA L LDVDF NKAK S P L P GDE TQHMGCV F CD P V F QE LVE L KHAA S CHPMHRGG

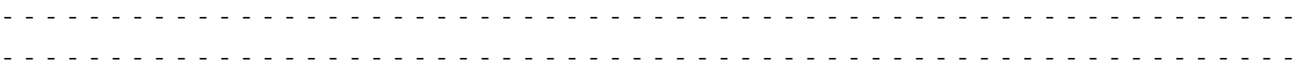

910

GAAGGGRG - GRGGRGRGRGRGRGNREDRR - . - . - -

PGRRQGRGRGRARR P PGK PNPRR P KDKMS A LAAY F V

Figure 1: Amino acid sequence alignment. Sequence of $L d \operatorname{TopIII} \beta$ (Ld) was aligned with the amino acid sequences of $H$. sapiens topoisomerase III $\beta(\mathrm{Hs})$, topoisomerase III from $S$. cerevisiae $(\mathrm{Sc})$ and $S$. pombe $(\mathrm{Sp})$ using CLUSTAL W. The amino acids are numbered on the top of the sequences. Active site motifs and other important conserved and identical residues are depicted in red. Green and blue indicate strongly similar and weakly similar amino acids, respectively. 


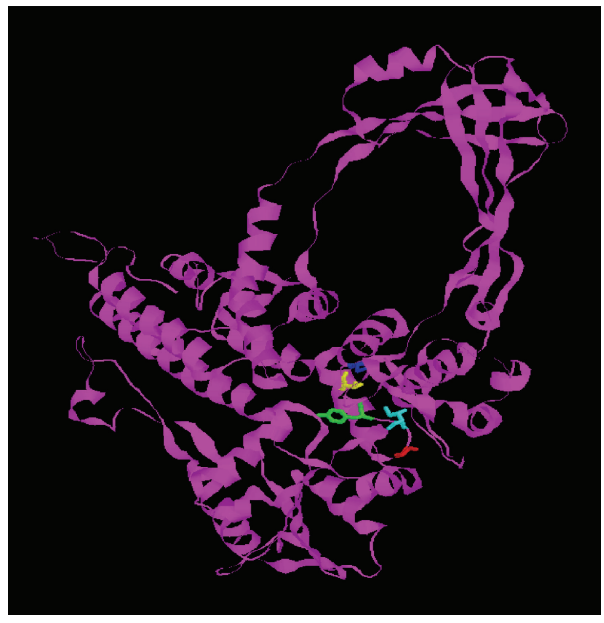

(a)

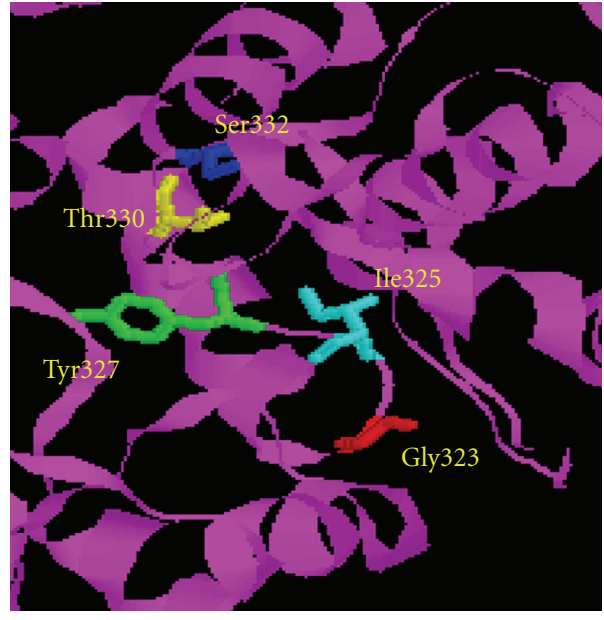

(b)

Figure 2: (a) Three-dimensional structure of $L d$ TopIII $\beta$. A ribbon structure representation of $L d$ TopIII $\beta$ generated based on the crystal structure of $E$. coli topo isomerase III. Catalytically conserved residues are represented in ball and stick format over the ribbon structure. (b) Close up view of $L d$ TopIII $\beta$ in which the amino acid residues that are vital for enzyme action are labeled and represented in ball and stick format. The positions of the amino acids are also mentioned.

TABle 1: Amino acids homology comparisons between Leishmania donovani topoisomerase III $\beta$ (866 amino acids) and other members of typeIA topoisomerases.

\begin{tabular}{lccc}
\hline Type IA topoisomerases & $\begin{array}{c}\text { Identity } \\
(\%)\end{array}$ & $\begin{array}{c}\text { Similarity } \\
(\%)\end{array}$ & $\begin{array}{c}\text { Size } \\
\text { (amino acids) }\end{array}$ \\
\hline LdTopIII $\alpha$ & 28.54 & 59.66 & 947 \\
LdTopIA & 13.22 & 48.56 & 812 \\
Human TopIII $\alpha$ & 27.14 & 55.47 & 1001 \\
Human TopIII $\beta$ & 46.22 & 76.09 & 862 \\
S. cerevisiae TopIII & 22.96 & 47.33 & 656 \\
S. pombe TopIII & 22.56 & 49.32 & 622 \\
\hline
\end{tabular}

to generate $L d T o p I I I \beta-p V T$ and transformed in top3 $\Delta$ yeast $S$. cerevisiae and Ura+ colonies were selected. Yeast cells transformed with vector pVT100U served as control in the complementation assay. The $L d$ TopIII $\beta$-pVT partially complemented the slow-growth of top $3 \Delta$ yeast (Figure $4(\mathrm{a})$ ). The improved growth rate was not observed in case of the vector control (Figure 4(a)). This observation suggests that $L d$ TopIII $\beta$ can be functionally expressed in yeast and shares functional similarity with $S$. cerevisiae top3 gene, which is consistent with earlier observations made with Drosophila and human topisomerase III $\beta$ proteins $[19,29]$. To observe this complementation of $L d \operatorname{TopIII} \beta$ in liquid medium a yeast growth curve analysis was carried out (Figure 4(b)). Equal amounts of the wild-type, topoisomerase 3 mutant yeast cells, topoisomerase 3 mutant yeast cells containing empty vector (pVT100U) and topoisomerase 3 mutant yeast cells containing $L d$ TopIII $\beta$ (grown overnight at $30^{\circ} \mathrm{C}$ ) were inoculated in fresh minimal medium and grown at $30^{\circ} \mathrm{C}$. At every $2 \mathrm{hr}$ interval up to $12 \mathrm{hrs}$, the growth was monitored and plotted.
3.5. Effects of Active Site Mutation of LdTopIII $\beta$ on Complementation Ability. Tyrosine 327 of LdTopIII $\beta$ was predicted to be the active site amino acid residue from sequence alignment analysis. In order to determine that $L d$ TopIII $\beta$ functionally complements the top 3 mutant yeast and the growth recovery was not due to any compensatory mechanism induced by $L d$ TopIII $\beta$ we carried out site directed mutagenesis. We have mutated the active site residue of $L d$ TopIII $\beta$ to phenylalanine (Y327F) by site directed mutagenesis and transformed in top3 mutant yeast. Transformed cells were grown on plate, as well as in liquid minimal media. It was observed that the active site mutant construct could not suppress the slow-growth of top3 mutant S. cerevisiae (Figures 5(a) and 5(b)) confirming role of active site tyrosine 327 in functional conservation of $L d$ TopIII $\beta$ inside mutant yeast cells.

3.6. The C-Terminal Domain of LdTopIII 3 Is Essential for In Vivo Complementation. The Leishmania enzyme has a Cterminal segment of amino acids with no counterpart in yeast protein. The leishmanial protein contains $\mathrm{Zn}$-binding motif at its C-terminus, which is absent in the topoisomerase III proteins of E. coli and yeast. The C-terminus residues of $E$. coli topoisomerase III have been previously shown to be involved in DNA binding [30]. To determine the role of the $\mathrm{C}$-terminal stretch of $L d$ TopIII $\beta$ in functional complementation, we have made a C-terminal deletion construct ( $L d$ TopIIIC $\Delta 258$ ) removing the 258 amino acids and transformed in topoisomerase III mutant yeast. The transformants were grown in plates and it was observed that the Cterminal deletion construct failed to rescue the mutant yeast from slow-growth (Figure 5(a)), suggesting essentiality of the C-terminal segment for functional complementation in vivo. To validate this observation in liquid medium we inoculated overnight grown cultures at $30^{\circ} \mathrm{C}$ in fresh minimal medium 


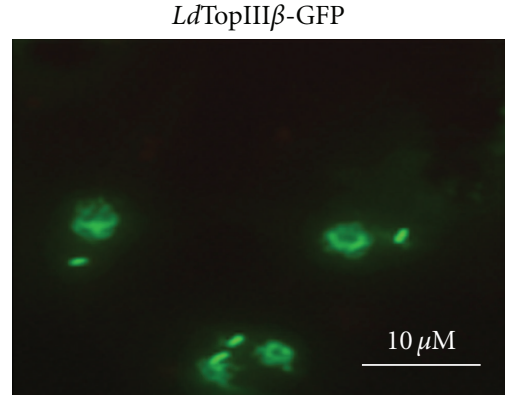

(a)

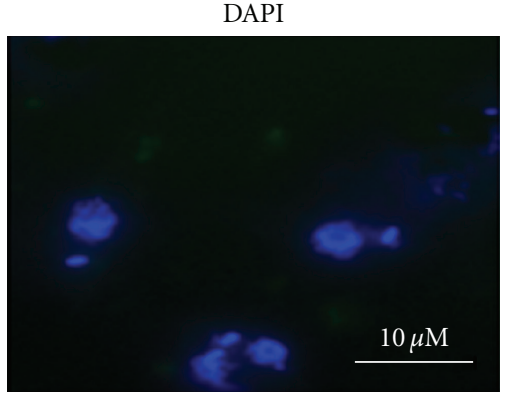

(b)

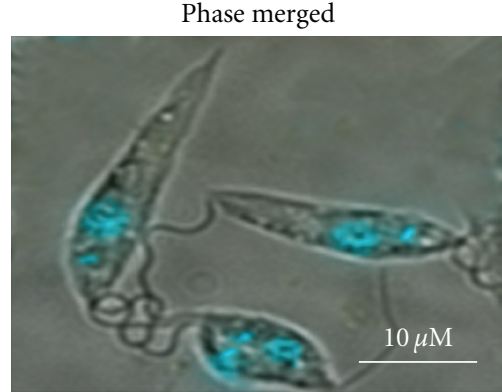

(c)

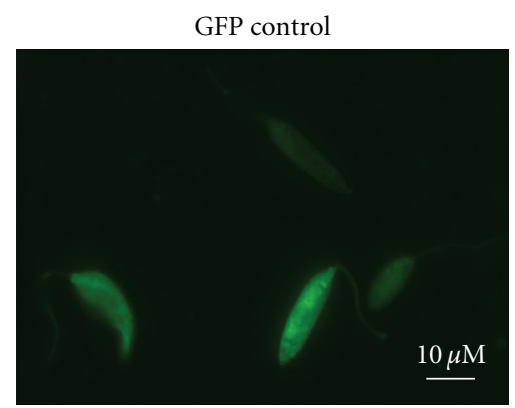

(d)

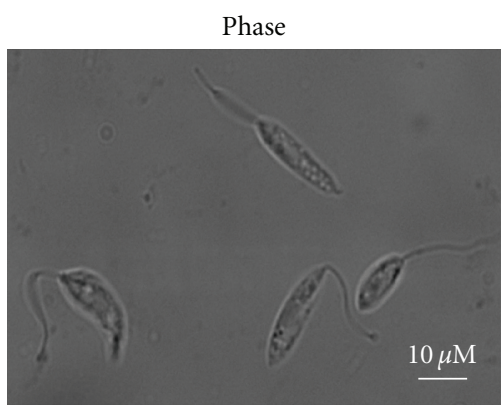

(e)

Figure 3: Localization $L d$ TopIII $\beta$. Wild-type construct of $L d$ TopIII $\beta$ was transfected in $L$. donovani parasites as C-terminally fused GFP proteins and viewed under fluorescence microscope (100x). Nucleus and kinetoplast DNA are visualized by DAPI staining.

and monitored their growth at $3 \mathrm{hr}$ intervals. The growth curve (Figure 5(b)) clearly indicates that LdTopIIIC $\Delta 258$ could not functionally complement the slow-growing topoisomerase III mutant yeast. This indicates that the conserved C-terminal region between amino acid residues 608-866 contains important residues that are required for in vivo function of $L d$ TopIIIC $\Delta 258$. To get a better insight into the functional characteristics of the enzyme, we next sought to obtain recombinant $L d$ TopIII $\beta$ protein in vitro.

\subsection{In Vitro Activity of Recombinant LdTopIII Protein.} $L d$ TopIII $\beta$ was cloned in bacterial expression vector $\mathrm{pET}-16 \mathrm{~b}$ and overexpressed in BL21 (DE3)-pLysS strain and induced with IPTG. But the overexpressed protein went to inclusion body and were found in the pellet as insoluble protein which could not be recovered in the soluble fraction in active state. However, to test the activity of the recombinant protein, we have used in vitro transcription-translation kit, which is specially designed for in vitro transcription and translation of target DNA to protein in a single reaction. The crude lysate containing the newly synthesized proteins were used for DNA relaxation assay. Figure 6(a) shows DNA relaxation by increasing amount of recombinant $L d$ TopIII $\beta$ (lanes $2-$ $8)$. Lane 1 is the DNA control. The results clearly show that the recombinant protein containing lysates were able to relax the negatively supercoiled DNA. To test that the activity was not coming from the lysate itself, we have carried out DNA relaxation activity with the empty vector containing lysate which contained insignificant amount of activity, shown in Figure 6(b) (lane 3). Lane 2 shows DNA relaxation activity by recombinant $L d$ TopIII $\beta$.

\section{Discussion}

The type IA topoisomerases are among the most conserved proteins in nature, and their presence in all organisms is supported by extensive biochemical and genomic sequence data $[2,4]$. This universal presence suggests that the type IA DNA topoisomerases play an indispensable role in one or more fundamental processes involving DNA, plausibly in the removal of double Holliday junctions [2]. Topoisomerases III $\alpha$ and III $\beta$ of kinetoplastid parasites seem to be orthologues of same kind of enzymes in other eukaryotes, notable for branching early within their respective groups. In the present study, for the first time we have identified functionally active DNA topoisomerase $\operatorname{III} \beta$ from $L$. donovani. Blast sequence alignments suggested topoisomerase III $\beta$ from Leishmania has high homology with human and drosophila topoisomerase III $\beta$. It shares many features, which are typical for other topoisomerase III $\beta$ proteins including the CXXC type of motifs and a long stretch of $\mathrm{G}$ and $\mathrm{R}$ residues at its C-terminus. GFP-fused $L d$ TopIII $\beta$ localized both inside the nucleus and the kinetoplast of $L$. donovani parasites indicating the involvement of $L d$ TopIII $\beta$ in DNA processing inside both the parasite organelle. Our results show for the first time the presence of an IA type of topoisomerase in the nucleus, as well as in the kinetoplast of Leishmania parasites. Previously, a IA type of topoisomerase from bacterial origin has been reported to be mitochondrial in T. brucei [24].

$L d$ TopIII $\beta$ could suppress the slow-growth phenotype of the mutant yeast indicating the functional conservation of topoisomerase III activity. The result is consistent with the 


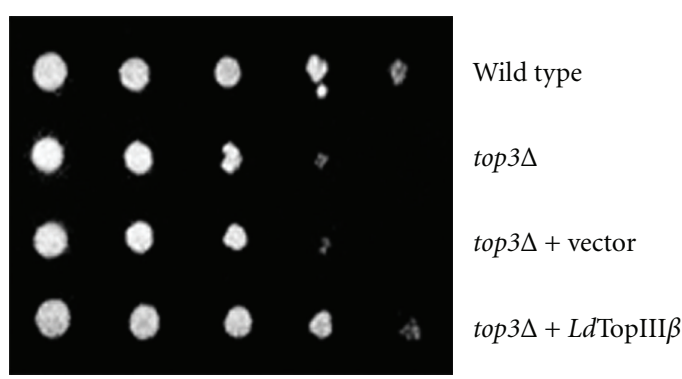

(a)

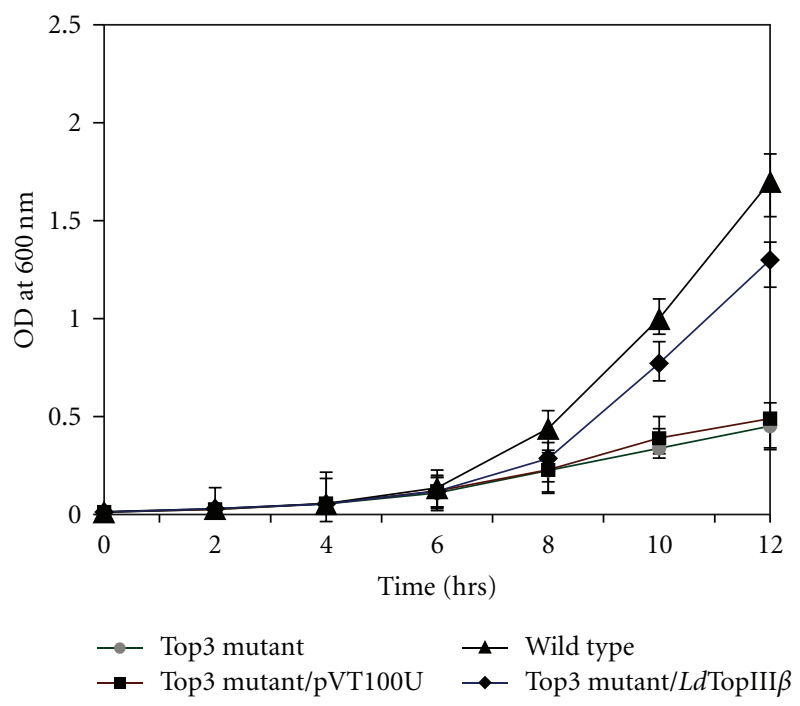

(b)

Figure 4: Functional complementation of $L d T$ TopIII $\beta$. (a) S. cerevisiae top $3 \Delta$ strain was transformed with a vector $\mathrm{pVT} 100 \mathrm{U}$ and the vector carrying wild-type $L d$ TopIII $\beta$. Transformed cells were streaked on solid synthetic minimal media and incubated at $28^{\circ} \mathrm{C}$. Ten-fold serial dilutions of exponentially growing wild-type strain, top $3 \Delta$ strain, top $3 \Delta$ strain harboring an empty vector, or top $3 \Delta$ strain harboring plasmid encoded $L d \operatorname{TopIII} \beta$, as indicated on the right, grown on the plate. (b) Growth rate of the above-described strains were measured in the liquid synthetic medium and $\mathrm{OD}_{600}$ was plotted against time. Results represent the means \pm standard errors of three independent experiments.

earlier observations made with human and Drosophila topoisomerase III $\beta$ enzymes. The C-terminal deletion construct of $L d T$ TopIII $\beta$ lacking its $\mathrm{Zn}$ binding domain was unable to rescue the topoisomerase III mutant yeast from slowgrowing phenotype revealing that the C-terminal 258 amino acids were indispensable for functional complementation of $L d T$ TopIII $\beta$ in vivo. Previous report reveals the requirement of the C-terminus region of bacterial topoisomerase III in substrate specificity [30]. It is possible that C-terminal end of the leishmanial topoisomerase III $\beta$ protein is essential for DNA binding which requires further investigations. Site directed mutagenesis study revealed that tyrosine at 327 position within the conserved amino acid stretch is the active site tyrosine of $L d T$ TopIII $\beta$ and when this tyrosine is mutated to phenylalanine, the protein failed to
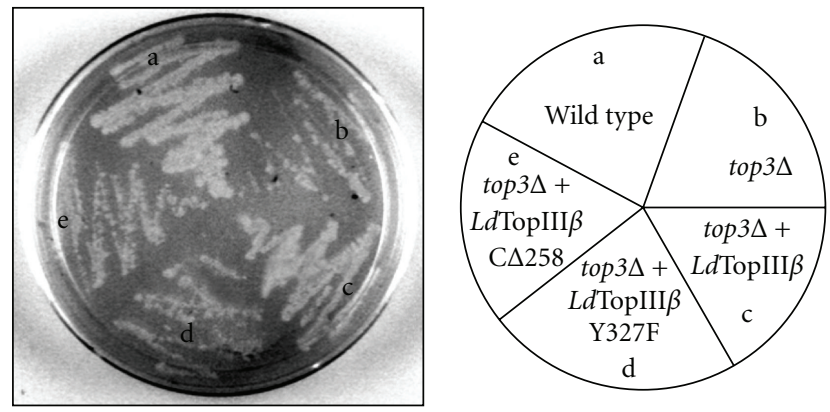

(a)

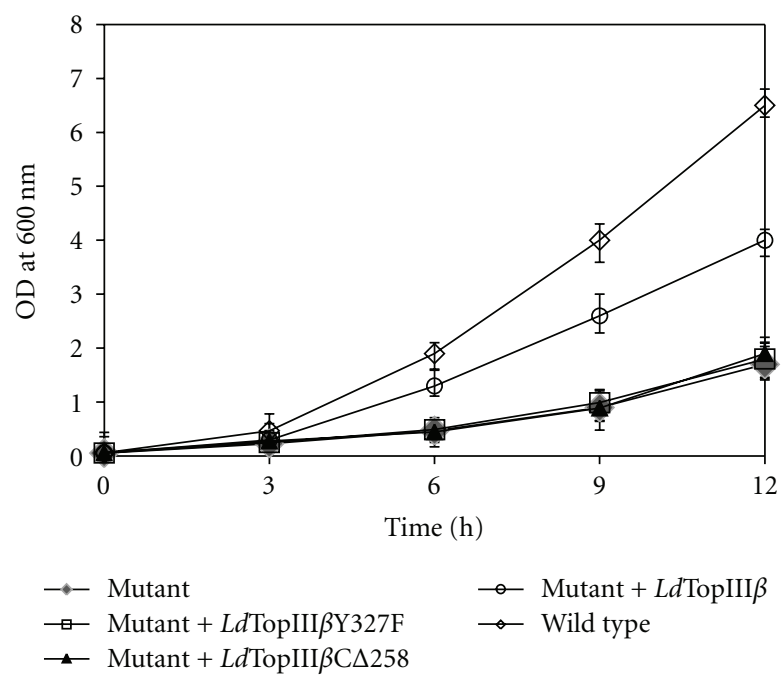

(b)

Figure 5: Complementation assay with mutant $L d \operatorname{TopIII} \beta$. (a) Topoisomerase III mutant yeast strain was transformed with the plasmid containing wild-type (c), active site mutant (d) and C-terminal deletion construct (e) of $L d \operatorname{TopIII} \beta$, separately. Transformed cells were streaked on solid synthetic minimal media and incubated at $30^{\circ} \mathrm{C}$. (b) Complementation assay as described above carried out in liquid synthetic medium and $\mathrm{OD}_{600}$ plotted against time. Results represent the means \pm standard errors of three independent experiments.

complement the slow-growing mutant yeasts. The result indicates towards involvement of the functionally active $L d$ TopIII $\beta$ in rescue of the mutant yeast from slow-growth. Our attempts to purify recombinant $L d$ TopIII $\beta$ enzymes in active state from bacteria were unsuccessful as the proteins consistently went to inclusion body. But we were able to study, for the first time, the in vitro DNA relaxation activity the recombinant topoisomerase III protein from the kinetoplastid parasite Leishmania, when synthesized using cell free in vitro transcription-translation kit. Altogether, this is the first report of functionally active topoisomerase III $\beta$ protein from unicellular kinetoplastid parasite Leishmania.

The biological functions of eukaryotic topoisomerse III proteins are intriguing. Important nonoverlapping function 


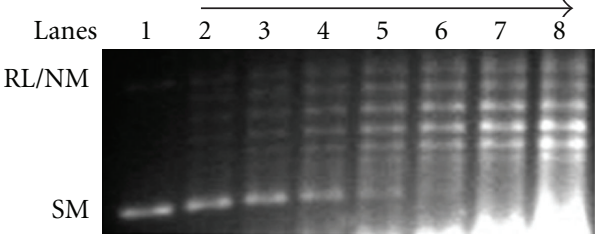

(a)

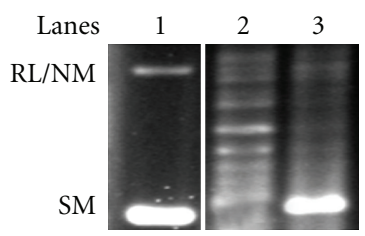

(b)

Figure 6: DNA relaxation assay by recombinant $L d T$ TopIII $\beta$. (a) Negatively super coiled DNA was incubated with $1,2,3,4,5,7$ and $10 \mu \mathrm{L}$ of recombinant $L d$ TopIII $\beta$ containing lysate for $30 \mathrm{~min}$ (lanes 2-8). Lane 1 is the DNA control. (b) DNA relaxation assay carried out with recombinant $L d \operatorname{TopIII} \beta$ (lane 2 ), and empty vector containing lysate (lane 3). Lane 1 is the DNA control.

of the two isozymes of topoisomerse III has been revealed by previous studies. The mouse-knockout experiments suggests, the $\alpha$ form is essential for embryonic development, whereas the $\beta$ form is critical for life span $[20,21]$. Genetic experiments in yeast have demonstrated that TOP3 plays a role in suppressing mitotic recombination and in resolving recombined homologous chromosomes during meiosis I $[14,31]$. Preferential cleavage of plasmid-based R- and D-loops, has been reported by Drosophila topoisomerase III $\beta$ [32]. Furthermore, the combined action of either yeast or bacterial topoisomerse III and the DNA helicase RecQ can promote the formation of DNA catenanes [33]. The unwinding action of a RecQ type helicase appears to generate a DNA structure that can be recognized by a topoisomerase III. RecQ helicases are also conserved in kinetoplastide parasites. The only report of functionally significant topoisomerase III $\alpha$ from kinetoplastide parasite came very recently, which describes that topoisomerse III $\alpha$ from Trypanosoma brucei influences antigenic variation by monitoring expression-site-associated VSG switching [25]. Existence of functionally active topoisomerase III protein in Leishmania indicates towards its role in DNA metabolism in the parasites, which requires further studies and might emerge as a new therapeutic target that can be exploited against the deadly parasites.

\section{Funding}

This work was supported by Network Project (NWP038) of Council of Scientific and Industrial Research (CSIR), Government of India to H. K. Majumder. B. Banerjee was supported by Senior Research Fellowship from CSIR, Government of India.

\section{Acknowledgments}

The authors thank professor S. Roy, the Director of Indian Institute of Chemical Biology for his interest in this work. They are grateful to professor S. M. Beverley for kindly gifting the Leishmania transfection vector and Dr. R. Rothstein for topoisomerase III mutant yeast strains.

\section{References}

[1] Y. H. Hsiang, R. Hertzberg, S. Hecht, and L. F. Liu, "Camptothecin induces protein-linked DNA breaks via mammalian DNA topoisomerase I," Journal of Biological Chemistry, vol. 260, no. 27, pp. 14873-14878, 1985.

[2] J. C. Wang, "Cellular roles of DNA topoisomerases: a molecular perspective," Nature Reviews Molecular Cell Biology, vol. 3, no. 6, pp. 430-440, 2002.

[3] J. C. Wang, "DNA topoisomerases," Annual Review of Biochemistry, vol. 65, pp. 635-692, 1996.

[4] J. J. Champoux, "DNA topoisomerases: structure, function, and mechanism," Annual Review of Biochemistry, vol. 70, pp. 369-413, 2001.

[5] J. J. Champoux and R. Dulbecco, "An activity from mammalian cells that untwists superhelical DNA-a possible swivel for DNA replication (polyoma-ethidium bromide-mouseembryo cells-dye binding assay)," Proceedings of the National Academy of Sciences of the United States of America, vol. 69, no. 1, pp. 143-146, 1972.

[6] R. A. Kim and J. C. Wang, "Identification of the yeast $\mathrm{TOP}_{3}$ gene product as a single strand-specific DNA topoisomerase," Journal of Biological Chemistry, vol. 267, no. 24, pp. 1717817185, 1992.

[7] Y. C. Tse-Dinh and J. C. Wang, "Complete nucleotide sequence of the topA gene encoding Escherichia coli DNA topoisomerase I," Journal of Molecular Biology, vol. 191, no. 3, pp. 321-331, 1986.

[8] R. J. DiGate and K. J. Marians, "Identification of a potent decatenating enzyme from Escherichia coli," Journal of Biological Chemistry, vol. 263, no. 26, pp. 13366-13373, 1988.

[9] R. J. DiGate and K. J. Marians, "Molecular cloning and DNA sequence analysis of Escherichia coli topB, the gene encoding topoisomerase III," Journal of Biological Chemistry, vol. 264, no. 30, pp. 17924-17930, 1989.

[10] M. Pastorcic,Ph.D. thesis, University of Chicago, 1982.

[11] K. S. Srivenugopal, D. Lockshon, and D. R. Morris, "Escherichia coli DNA topoisomerase III: purification and characterization of a new type I enzyme," Biochemistry, vol. 23, no. 9, pp. 1899-1906, 1984.

[12] A. Goodwin, S. W. Wang, T. Toda, C. Norbury, and I. D. Hickson, "Topoisomerase III is essential for accurate nuclear division in Schizosaccharomyces pombe," Nucleic Acids Research, vol. 27, no. 20, pp. 4050-4058, 1999.

[13] M. Oh, I. S. Choi, and S. D. Park, "Topoisomerase III is required for accurate DNA replication and chromosome segregation in Schizosaccharomyces pombe," Nucleic Acids Research, vol. 30, no. 18, pp. 4022-4031, 2002.

[14] J. W. Wallis, G. Chrebet, G. Brodsky, M. Rolfe, and R. Rothstein, "A hyper-recombination mutation in S. cerevisiae identifies a novel eukaryotic topoisomerase," Cell, vol. 58, no. 2, pp. 409-419, 1989. 
[15] R. K. Chakraverty, J. M. Kearsey, T. J. Oakley et al., “Topoisomerase III acts upstream of Rad53p in the S-phase DNA damage checkpoint," Molecular and Cellular Biology, vol. 21, no. 21, pp. 7150-7162, 2001.

[16] R. Hanai, P. R. Caron, and J. C. Wang, "Human $\mathrm{TOP}_{3}$ : a singlecopy gene encoding DNA topoisomerase III," Proceedings of the National Academy of Sciences of the United States of America, vol. 93, no. 8, pp. 3653-3657, 1996.

[17] T. Seki, M. Seki, R. Onodera, T. Katada, and T. Enomoto, "Cloning of cDNA encoding a novel mouse DNA topoisomerase III (topo III $\beta$ ) possessing negatively supercoiled DNA relaxing activity, whose message is highly expressed in the testis," Journal of Biological Chemistry, vol. 273, no. 44, pp. 28553-28556, 1998.

[18] H. Goulaouic, T. Roulon, O. Flamand, L. Grondard, F. Lavelle, and J. F. Riou, "Purification and characterization of human DNA topoisomerase III $\alpha$," Nucleic Acids Research, vol. 27, no. 12, pp. 2443-2450, 1999.

[19] T. M. Wilson, A. D. Chen, and T. S. Hsieh, "Cloning and characterization of Drosophila topoisomerase III $\beta$. Relaxation of hypernegatively supercoiled DNA," Journal of Biological Chemistry, vol. 275, no. 3, pp. 1533-1540, 2000.

[20] W. Li and J. C. Wang, "Mammalian DNA topoisomerase III $\alpha$ is essential in early embryogenesis," Proceedings of the National Academy of Sciences of the United States of America, vol. 95, no. 3, pp. 1010-1013, 1998.

[21] K. Y. Kwan and J. C. Wang, "Mice lacking DNA topoisomerase III $\beta$ develop to maturity but show a reduced mean lifespan," Proceedings of the National Academy of Sciences of the United States of America, vol. 98, no. 10, pp. 5717-5721, 2001.

[22] K. Y. Kwan, P. B. Moens, and J. C. Wang, "Infertility and aneuploidy in mice lacking a type IA DNA topoisomerase III $\beta$," Proceedings of the National Academy of Sciences of the United States of America, vol. 100, no. 5, pp. 2526-2531, 2003.

[23] B. B. Das, T. Sengupta, A. Ganguly, and H. K. Majumder, "Topoisomerases of kinetoplastid parasites: why so fascinating?” Molecular Microbiology, vol. 62, no. 4, pp. 917-927, 2006.

[24] J. R. Scocca and T. A. Shapiro, "A mitochondrial topoisomerase IA essential for late theta structure resolution in African trypanosomes," Molecular Microbiology, vol. 67, no. 4, pp. 820-829, 2008.

[25] H.-S. Kim and G. A. M. Cross, "TOPO3 $\alpha$ inlfluences antigenic variation by monitoring expression-site-associated VSG switching in Trypanosoma brucei," PLoS Pathogens, vol. 6, no. 7, Article ID e1000992, 2010.

[26] G. M. Kapler, C. M. Coburn, and S. M. Beverley, "Stable transfection of the human parasite Leishmania major delineates a 30-kilobase region sufficient for extrachromosomal replication and expression," Molecular and Cellular Biology, vol. 10, no. 3, pp. 1084-1094, 1990.

[27] T. Vernet, D. Dignard, and D. Y. Thomas, "A family of yeast expression vectors containing the phage $\mathrm{f} 1$ intergenic region," Gene, vol. 52, no. 2-3, pp. 225-233, 1987.

[28] D.-C. Chen, B.-C. Yang, and T.-T. Kuo, "One-step transformation of yeast in stationary phase," Current Genetics, vol. 21, no. 1, pp. 83-84, 1992.

[29] S. W. Ng, Y. Liu, K. T. Hasselblatt, S. C. Mok, and R. S. Berkowitz, "A new human topoisomerase III that interacts with SGS1 protein," Nucleic Acids Research, vol. 27, no. 4, pp. 993-1000, 1999.

[30] H. L. Zhang and R. J. DiGate, “The carboxyl-terminal residues of Escherichia coli DNA topoisomerase III are involved in substrate binding," Journal of Biological Chemistry, vol. 269, no. 12, pp. 9052-9059, 1994.
[31] S. Gangloff, B. De Massy, A. Lane, R. Rothstein, and F. Fabre, "The essential role of yeast topoisomerase III in meiosis depends on recombination," The EMBO Journal, vol. 18, no. 6, pp. 1701-1711, 1999.

[32] T. Wilson-Sali and T. S. Hsieh, "Preferential cleavage of plasmid-based R-loops and D-loops by Drosophila topoisomerase III $\beta$," Proceedings of the National Academy of Sciences of the United States of America, vol. 99, no. 12, pp. 7974-7979, 2002.

[33] F. G. Harmon, R. J. DiGate, and S. C. Kowalczykowski, "RecQ helicase and topoisomerase III comprise a novel DNA strand passage function: a conserved mechanism for control of DNA recombination," Molecular Cell, vol. 3, no. 5, pp. 611-620, 1999. 

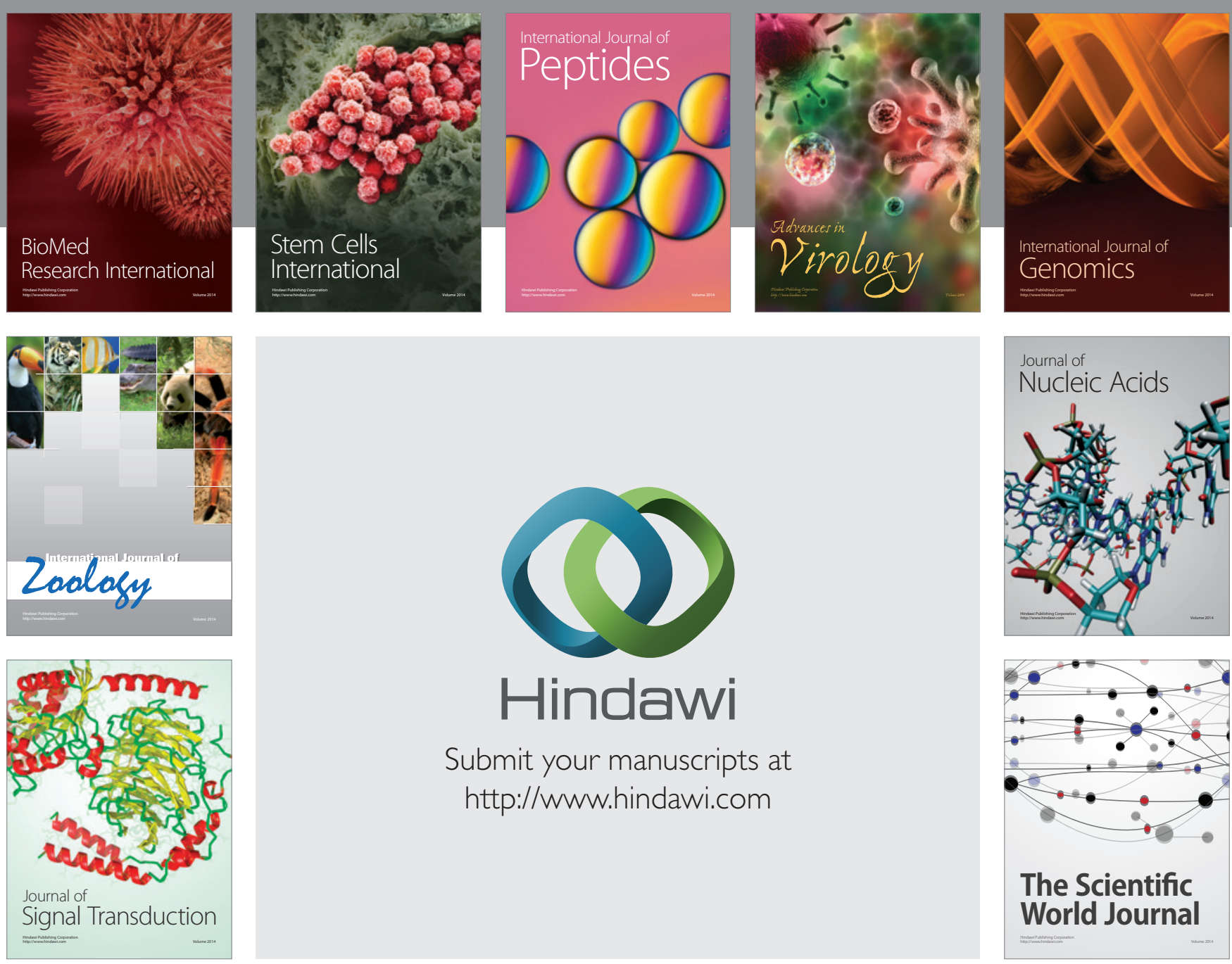

Submit your manuscripts at

http://www.hindawi.com
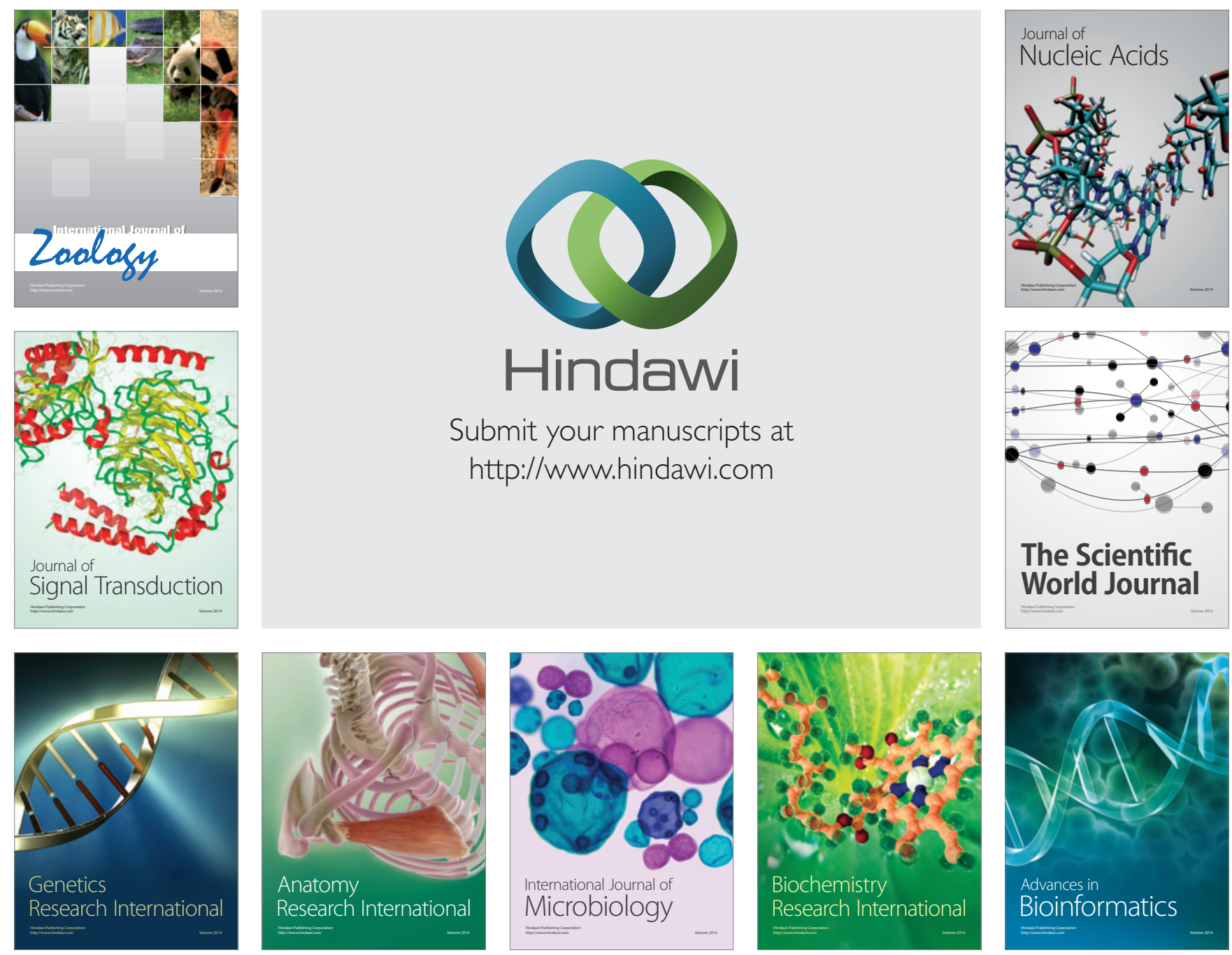

The Scientific World Journal
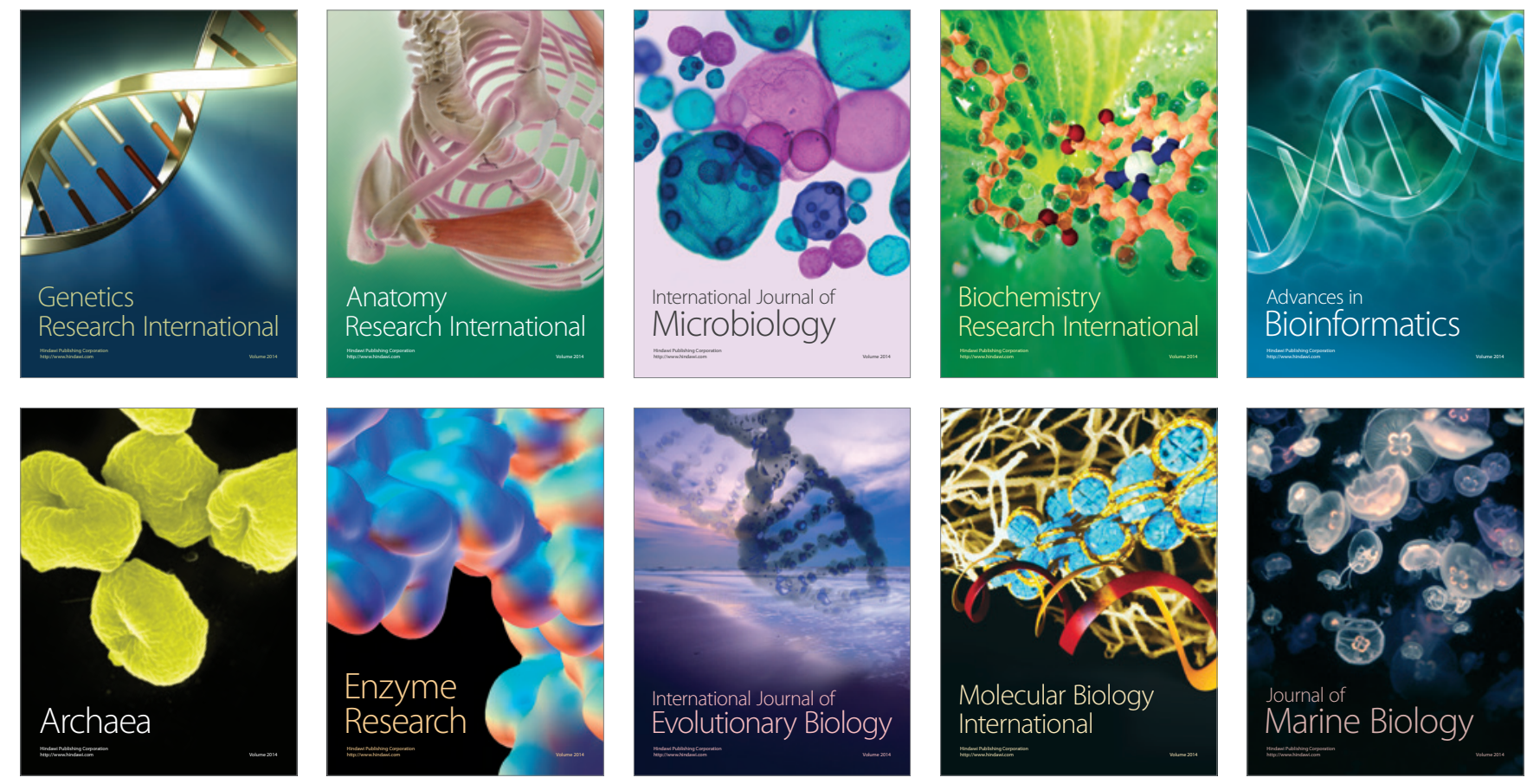